\title{
Numerical Analysis for Cavitation flow of the Depressurization Orifice of an Auxilary Feedwater Pump
}

\author{
JUNEHO BAE ${ }^{1}$, GONG-HEE LEE ${ }^{1}$ \\ ${ }^{1}$ Department of Regulatory Assessment, Korea Institute of Nuclear Safety \\ 62 Gwahak-ro, Daejeon, 43142 Republic of Korea \\ K733bjh@kins.re.kr
}

\section{Extended Abstract}

Nuclear power plant operators should check the performance of the pumps and valves that perform safety functions through In-Service Test(IST), and evaluate the degree of vulnerability over time. The Piping leakage occurred at the socket welding part of the Depressurization orifice of an Auxiliary Feedwater Pump in nuclear power plant of Korea. The operators of Nuclear Power plant suggested a Cavitation as the cause of the leakage by measuring the vibration of the pipe according to the flow rate. Cavitation is phenomenon that occurs in the low pressure part and is one of the main causes that impair the safety of the nuclear power plant system because it can occur in various devices such as pumps, valves, and measuring devices. From the regulatory point of view, the purpose of this numerical analysis is to verify operator's result by CFD. In this study, the Depressurization Orifice consisting of eight stages was modelled the same as the orifice used in the actual nuclear power plant, and was simulated for the effect of cavitation on this orifice using commercial CFD software, ANSYS Fluent with hexahedral grid system, generated by a grid generation software, ICEM-CFD. The flow of Auxiliary Feedwater Pump was assumed to be unsteady, incompressible, turbulent and multi-phase flow. Volume of Fluid(VOF) method and kw SST \& k-e RNG Reynolds averaged Navier-stokes turbulent models was used for simulation.

In this study, verification simulation was performed for the piping leakage caused by the cavitation in the pressure reducing orifice of the Auxiliary Feedwater Pump of nuclear power plant. As a result, the corrective action of Nuclear Power Plant operator for the leakage was confirmed.

\section{Acknowledgement}

This work was supported by the Nuclear Safety Research Program through the Korea Foundation of Nuclear Safety (KOFONS) using the financial resource granted by the Nuclear Safety and Security Commission (NSSC) of the Republic of Korea (NO.1805007).

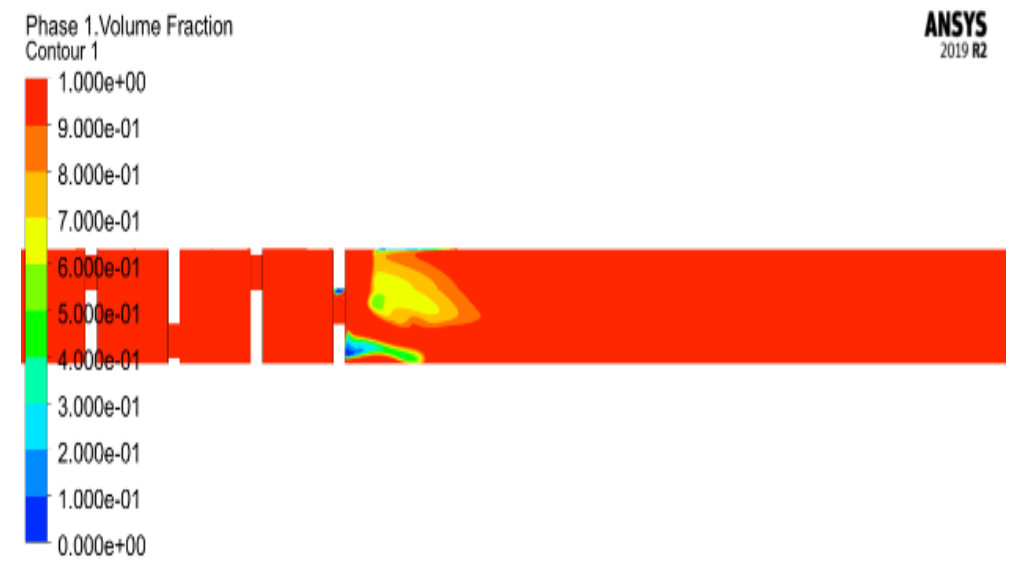

Fig. 1 Void Fraction of k-w SST model simulation 
$-7.000 \theta-01$

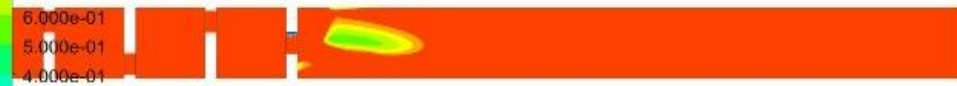

$3.0000-01$

2.000e-01

$1.000 \mathrm{e}-01$

$0.000 \mathrm{e}+00$

Fig. 2 Void Fraction of k-e RNG model simulation 